\title{
燕山地区表土花粉与植被间的数量关系
}

\author{
杨振京 ${ }^{1,2}$ 许清海 ${ }^{3}$ 孟令尧 4 阳小兰 ${ }^{4}$ 王开发 ${ }^{5}$ \\ (1 中国科学院植物研究所植被数量生态学重点实验室, 北京 100093) \\ (2 中国地质科学院水文地质环境地质研究所, 河北正定 050803) \\ （3 河北师范大学资源与环境学院,石家庄 050016) \\ (4 河北省科学院地理研究所, 石家庄 050011) (5 同济大学海洋地质与地球物理系, 上海 200092)
}

\begin{abstract}
摘 要 根据表土花粉分析和植被样方调查, 燕山地区各植被带的表土孢粉组合在总体面貌上代表了植被组成, 但狍粉组合不等于植被组成, 而影响其差异的原因是狍粉保存、孢粉产量、外来狍粉和狍粉鉴定。表土花粉的代表 性因种属不同而差异颇大, 乔木植物花粉中松( Pinus)、桦( Betula)、胡桃( Juglans)和栗 (Castanea) 具超代表性, 而栎 ( Quercus)、鹅尔枥(Carpinus)和杨(Populus)具低代表性; 灌木植物花粉中花椒属(Zanthoxylum)具超代表性, 蓄薇科和 榛( Corylus) 多具低代表性; 草本植物花粉中蒿( Artemisia)、僽科、香蒲( Typha)、唇形科、苶科、毛茛科、伞形科和唐松 草( Thalictrum)具超代表性, 禾本科、虎耳草科、葎草( Humulus)、莎草科、豆科、石竹科和旋花科等具低代表性。同一 花粉在不同的植被带中其 $R$ 值也有一定的差异,一般地说在远离主要花粉源的植被带中, 该花粉的 $R$ 值偏低, 而 在花粉源产地则 $R$ 值偏高。
\end{abstract}

关键词 表土狍粉 植物群落 $R$ 值 燕山地区

\section{QUANTITATIVE RELATIONSHIP BETWEEN POLLEN IN THE SURFACE SOIL AND VEGETATION IN THE YANSHAN AREA}

\author{
YANG Zhen-Jing $^{1,2}$ XU Qing-Hai ${ }^{3} \quad$ MENG Ling-Yao ${ }^{4}$ YANG Xiao-Lan ${ }^{4}$ and WANG Kai-Fa ${ }^{5}$ \\ (1 Laboratory of Quantitative Vegetation Ecology, Institute of Botany, the Chinese Academy of Sciences, Beijing 100093, China) \\ (2 Institute of Hydrologic and Environmental Geology, the Chinese Academy of Geological Sciences, Zhengding, Hebei 050803, China) \\ (3 College of Resources and Environment, Hebei Normal University, Shijiazhuang 050016, China) \\ (4 Institute of Geography, Hebei Academy of Sciences, Shijiazhuang 050011, China) \\ (5 Department of Marine Geology and Geophysics, Tongji University, Shanghai 200092, China)
}

\begin{abstract}
This study explored the quantitative relationship between pollen in the surface soil and vegetation in the Yanshan area. Data were collected from the region between about $39^{\circ} 00^{\prime}-40^{\circ} 50^{\prime} \mathrm{N}$ and between $117^{\circ} 10^{\prime}$ $-119^{\circ} 50^{\prime} \mathrm{E}$ from $2082 \mathrm{~m}$ elevation in the Yanshan Mountains to $0 \mathrm{~m}$ at the seashore of the Bohai Sea. The samples of pollen in the surface soil were collected from 53 locations at about $100 \mathrm{~m}$ elevational intervals in Yanshan Mountainous area and at about $20 \mathrm{~km}$ level intervals in the plain between Yanshan mountain and Bohai Sea seashore. At the same time of pollen sampling in the surface soil, investigation of the vegetation was also done. Then, $R$ value (representation of pollen) was calculated with pollen percentage and vegetation investigation. According to sampling of pollen in surface soil and vegetation investigation, the relationship between soil surface pollen and modern vegetation was quantitatively analyzed. Results showed that the surface pollen assemblages of all vegetation zones in Yanshan area basically represent vegetation composition, but the pollen assemblages are not equal to the vegetation composition. This is due to the influences of pollen preservation, pollen production, foreign pollen and pollen identification. The representation of pollen in surface soil is very different in families and genera. The tree pollens such as Pinus, Betula, Juglans and Castanea are over-represented, but Quercus, Carpinus and Populus are under-represented; the shrub pollen such as Zanthoxylum is over-represented, Rosaceae and Corylus are under-represented; the herb pollens such as Artemisi$a$, Chenopodiaceae, Typha, Labiatae, Polygonaceae, Ranunculaceae, Umbelliferae and Thalictrum are overrepresented, while others such as Gramineae, Saxifragaceae, Humulus, Cyperaceae, Leguminosae, Caryophyllaceae and Convolvulaceae are under-represented. The same pollen in different vegetation zones has different $R$ value. Generally, $R$ value of the pollen in the vegetation zones far away from the main pollen sources is lower than that in the places of main pollen sources. The change of $R$ value is also influenced by
\end{abstract} 基金 (2003033253)

河北省科学院地理研究所李庆辰研究员、于和平工程师和司机聂石录师傅参加了野外工作, 河北师范大学刘濂教授、中国科学院植物研究 所孔昭宸和倪健研究员给予了指导, 谨致谢忱!

E-mail: yzj1966@yahoo.com 
pollen preservation, pollen production, and foreign pollen .

Key words Soil surface pollen, Plant community, $R$ value, Yanshan area

由于孢粉的产量、传播、结构和保存等方面的不 同, 导致了孢粉组合与实际植被之间总是存在一定 的差异, 从而产生了孢粉的代表性问题, 即组合中的 孢粉数量和百分比、浓度、沉积率比例与实际植被中 该植物的数量和比例并非完全一致,而通过研究表 土孢粉谱与大气花粉雨, 弄清狍粉与植被的对应关 系是解决这一问题的关键方法之一。其中 Davis (1963)提出的校正系数 $R$ 值的概念就是为了进行 植物和花粉之间数量关系的研究, 即为了能根据花 粉组成来推论该种植物的数量。

由于中国原始植被多受破坏, 现存的大都分布 在环境艰苦、交通不便的地方, 故 $R$ 值的研究尚不 全面, 但有少量报道(李文渏等, 1993; 张佳华等, 1996; 童国榜等,1996)。燕山地区位于华北地区的 北部, 是我国北方农牧交错地带的南缘, 燕山山脉横 亘于京、津、冀的北部，山区地貌峰谷参差，山势高 峻, 平原广开为农田, 自然环境垂直分异明显, 其气 候、植被随海拔高程的变化呈带状分布。值得一提 的是, 尽管燕山地区自然植被遭到破坏, 但现代天然 次生林保存较好, 取得的表土花粉谱有助于全面地 解释该区花粉的散布特征,通过系统地研究该区花 粉与植被的关系, 将为我国孢粉与生态环境的研究 增添新的内容, 其 $R$ 值的研究显然具有十分重要的 意义。

\section{1 样品与分析方法}

\section{1 表土狍粉取样}

笔者依据狍粉学野外工作规则 (王开发等, 1983；1988; 徐馨等, 1992), 在研究区内的表土花粉 研究工作选择了雾灵山、都山和响山等植被较好的 地带从山顶到海边分别做了 3 条剖面(图 1), 分别 是:1)雾灵山-黄崖关-宁河-北塘 (19 个样点);2)都 山-青龙-卢龙-乐亭-捞鱼尖 (20 个样点); 3 ) 响山( 背 牛顶)-石寨-榆关-北戴河 (14 个样点)。每条剖面采 样间距为: 在山区海拔垂直高度 $100 \mathrm{~m}$ 左右, 山前滨 海平原水平距离 $20 \mathrm{~km}$ 左右。表土样品的采集与采 样点周围植被的调查同时进行。表土样品主要采集 林下表层土样和苔藓样,共采集了 53 块表土孢粉样 品, 在镜下共统计鉴定孢粉19917粒, 平均每个样品 约 376 粒, 这些孢粉分属 62 个科属植物类型, 均为 燕山地区的现生植物。

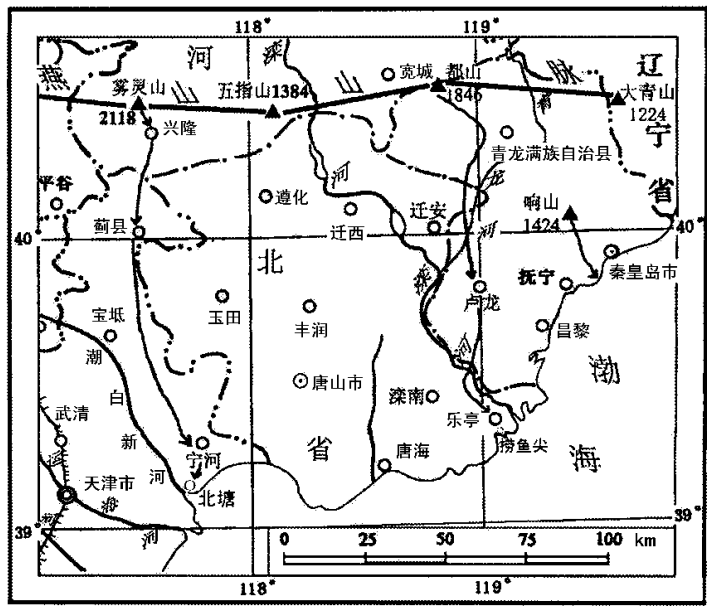

图 1 燕山地区表土狍粉剖面路线略图

Fig. 1 The field investigation and sampling line in Yanshan area $\rightarrow$ 表土狍粉采样路线 Sampling line

\section{2 植被调查}

采集表土孢粉样品的同时, 在取样点周围 $20 \mathrm{~m} \times 20 \mathrm{~m}$ 范围内做植被调查。主要记录取样点 周围植物群落中的植物种类及主要植物的丰度。植 物丰度用估测的盖度 (投影盖度)表示(童国榜等, 1996), 首先估测乔木、灌木及草本各自的总盖度, 然 后分别统计各属种的盖度, 其计算方法与狍粉百分 数的算法一致。

\section{$1.3 R$ 值的计算}

$R$ 值的计算采用公式 (Davis, 1963) : $R=P / V$, 式中, $P$ 为某种植物的狍粉百分含量; $V$ 为该种植物 在植被样方中的百分含量; 把 $R>1$ 称为超代表, $R<1$ 称为低代表, $R=1$ 称为适中代表。

\section{2 花粉与母体植物的数量关系}

2.1 狍粉成分与植被成分

通常, 在林中进行植被调查和孢粉取样时, 记录 样方中的植物种类成分, 不能全部出现在样方内的 表土孢粉组合中, 孢粉组合中的孢粉成分, 也不全是 在样方中有记录的。或者说, 表土样品中出现的不 全是所在群落生长植物的孢粉。根据实验和统计, 乔木植物与花粉的相同率，一般仅在 $40 \% \sim 60 \%$ 范 围内, 另有 $60 \% \sim 40 \%$ 的乔木成分是不相同的(李 文渏, 1998)。如雾灵山针阔混交林内 (表 1), 孢粉 与植物的相同率为 $55.36 \%$ 。

\section{$2.2 R$ 值的获得}

笔者在燕山地区各植被带中做了花粉与植物的 
表 1 雾灵山针阔混交林中出现在样方中的植物与 出现在表土中的花粉成分

Table 1 The plants in sample plot and pollens in surface samples in the coniferous and broad-leaved mixed forest of Wulingshan Mountain

\begin{tabular}{ccc}
\hline & 出现在植 & 出现在孢 \\
植物名称 & 被样方中 & 粉组合中 \\
Plant name & In sample & In pollen \\
& plot & assemblages
\end{tabular}

华北落叶松 Larix principis-rupprechtii

油松 Pinus tabulaeformis

云杉 Picea spp.

冷杉 Abies spp.

蒙古栋 Quercus mongolica

辽东栋 $Q$. liaotungensis

白桦 Betula platyphylla

棘皮桦 B. dahurica

核桃 Juglans regia

山核桃 Carya

柳 Salix

栗 Castanea

椴 Tilia

牛迭肚 Rubus crataegifolius

三裂绣线菊 Spiraea trilobata

毛榛 Corylus mandshurica

胡颓子科 Eleagnaceae

麻黄 Ephedra

毛茛科 Ranunculaceae

溲疏 Deutzia

小花溲疏 D. parviflora

牛尾蒿 Artemisia subdigitaea

柳叶蒿 A. integrifolia

蓝蓦香茶菜 Isodon glaucocalyz

尖齿粘苏 Phlomis dentosa

河北鹅观草 Roegneria hondai

硬质早熟禾 Poa sphondylode

大臭草 Melica turczaninoviana

藜科 Chenopodiaceae

伞形科 Umbelliferae

蓼科 Polygonaceae

五角枫 Acer mono

鸡爪槭 Acer palmatum

山杨 Populus davidiana

漆树 Rhus verniciflua

柿树 Diospyros kak

刺五加 Acanthopanax senticosus

接骨木 Sambucus williamsii

照山白 Rhododendron micranthum

蒙古英口 Viburnum mongolicum

(关东)丁香 Syringa velutina

顺坡溜 Carex lanceolata

雉隐天冬 (龙须草) Asparagus scoberioides

蓬子菜 Galium verum

桤木 Alnus

我耳枥 Carpinus

雪柳 Fontanesia

车前 Plantago

龙胆科 Gentianaceae

黑三棱 Sparganium

葎草 Humulus

柳叶菜 Epilobium

十字花科 Cruciferae

报春花科 Primulaceae

中华卷柏 Selaginella sinensis

水龙骨 Polypodium

*: 表示某种植物在植被样方或狍粉组合中出现 Denoting plant in sample plot or in pollen assemblage
对比调查与研究, 采用乔木植物花粉对应乔木植物 树种, 灌木草本植物花粉对应灌草从植物种类计算 百分含量, 然后计算 $R$ 值, 结果见表 2、表 3、表 4, 进 而得到了该区一些常见花粉的平均 $R$ 值(表 5 ), 从 一定程度上揭示了二者之间的数量关系。

由以上表格的 $R$ 值结果可知, 木本植物花粉松 (Pinus)、桦 (Betula)、胡桃 (Juglans)和栗 (Castanea) 具超代表性,而栋( Quercus)、鹅耳㭁(Carpinus)和杨 (Populus) 具低代表性; 灌木植物花粉花椒属 (Zanthoxylum) 具超代表性, 蓠薇科和榛(Corylus) 具低代 表性; 草本植物花粉蒿 (Artemisia) 、藜科、香蒲 ( Ty$p h a$ )、唇形科、苶科、毛莨科、伞形科和唐松草( Thalictrum) 具超代表性, 禾本科、虎耳草科、葎草 (Humulus )、莎草科、豆科、石竹科和旋花科等具低代表性。

\section{3 讨 论}

\section{1 植物与孢粉种类成分不一致的原因}

形成这种植物与孢粉种类成分不一致的现象主 要有 4 方面的原因, 即孢粉保存、孢粉产量、外来孢 粉和孢粉鉴定。

1)孢粉的保存: 有些孢粉外壁薄且脆弱, 不易保 存于沉积物中, 所以在表土孢粉谱中缺失, 例如杨属 和柏科植物花粉。

2)孢粉产量与统计量: 有些种类的植物在植被 中出现率较低, 如果其花粉产量又低的话, 则它们在 表土孢粉谱中也很难出现, 只有当统计到足够的数 量时才有可能偶尔见到。前人以往提出的统计 150 粒乔木花粉, 这对温带的森林植被是可取的, 在亚热 带地区, 由于植物种类繁多, 需做更大量统计, 一般 450 粒乔木花粉是必要的, 对此, 姚祖驹提出用极大 似然估值 (The maximum likelihood estimate), 来计算不 同花粉组合类型所需统计的花粉数量 (李文渏等, 1993)。

3)外来孢粉: 凡未见出现在记录样方中的孢粉 种类, 都可以被看作是外来植物的孢粉 (李文渏, 1998)。但实际上几乎所有孢粉都有可能散布到群 落以外的一定距离, 而形成那里的外来孢粉, 它们将 和本地狍粉混合堆积在一起。从而使所有表土中的 孢粉组合必定是本地和外来狍粉的混合组合。而且 同一种植物的每粒狍粉可能是本地的, 也可能是外 来的, 这是无法判别的。也就是说, 表土孢粉组合, 具有本地的和外来的双重性质。狍粉传播的自然条 件, 如风、流水和地形等, 会对于本地的孢粉数量产 生影响。当外来孢粉的种属与本地植物不一致时, 
表 2 雾灵山-北塘剖面常见花粉 $R$ 值

Table 2 The $R$ value of common pollens in surface samples on Wulingshan-Beitang Section

\begin{tabular}{|c|c|c|c|c|c|}
\hline $\begin{array}{l}\text { 植物 } \\
\text { Plants }\end{array}$ & $\begin{array}{l}\text { 山地草甸 } \\
\text { Montane } \\
\text { meadow }\end{array}$ & $\begin{array}{c}\text { 针阔混交林 } \\
\text { Coniferous } \\
\text { and broad-leaved } \\
\text { mixed forest }\end{array}$ & $\begin{array}{c}\text { 灌草丛 } \\
\text { Montane brushwood } \\
\text { and tussock }\end{array}$ & $\begin{array}{c}\text { 滨海平原草甸 } \\
\text { Meadow in } \\
\text { seashore plain }\end{array}$ & $\begin{array}{c}\text { 滨海盐生草甸 } \\
\text { Meadow/Saline meadow } \\
\text { in seashore }\end{array}$ \\
\hline 松 Pinus & 0.91 & 4.04 & & & \\
\hline 柳 Salix & & & & 5.59 & \\
\hline 栋 Quercus & & 0.20 & & & \\
\hline 栗 Castanea & & & 4.21 & & \\
\hline 桦 Betula & 3.24 & 2.03 & & & \\
\hline 胡桃 Juglans & & 0.16 & & & \\
\hline 榛 Corylus & & 0.27 & & & \\
\hline 葍薇科 Rosaceae & 0.77 & 0.11 & 0.23 & 4.26 & \\
\hline 蒿 Artemisia & 5.34 & 8.48 & 9.78 & 3.32 & \\
\hline 藜科 Chenopodiaceae & & & 1.86 & 7.83 & 24.43 \\
\hline 禾本科 Gramineae & 0.02 & 0.06 & 0.44 & 0.03 & 0.04 \\
\hline 菊科 Compositae & 0.51 & & 0.56 & 1.59 & \\
\hline 香蒲 Typha & & & & 9.79 & \\
\hline 虎耳草科 Saxifragaceae & & 1.40 & & & \\
\hline 唇形科 Labiatae & 0.70 & 0.59 & 4.47 & 3.98 & \\
\hline 蓼科 Polygonaceae & 6.33 & & & 3.78 & \\
\hline 毛茛科 Ranunculaceae & 3.78 & 1.15 & & & \\
\hline 葎草 Humulus & & & 1.16 & 1.54 & \\
\hline 伞形科 Umbelliferae & 10.46 & & & & \\
\hline 唐松草 Thalictrum & 1.20 & 1.98 & 3.02 & & \\
\hline
\end{tabular}

表 3 都山-捞鱼尖剖面常见花粉 $R$ 值

Table 3 The $R$ value of common pollens in surface samples on Dushan-Laoyujian Section

\begin{tabular}{|c|c|c|c|c|c|}
\hline $\begin{array}{l}\text { 植物 } \\
\text { Plants }\end{array}$ & $\begin{array}{c}\text { 桦木林 } \\
\text { Betula } \\
\text { woods }\end{array}$ & $\begin{array}{c}\text { 针阔混交林 } \\
\text { Coniferous } \\
\text { and broad-leaved } \\
\text { mixed forest } \\
\end{array}$ & $\begin{array}{l}\text { 山地草原 } \\
\text { Montane } \\
\text { grassland }\end{array}$ & $\begin{array}{c}\text { 滨海平原草甸 } \\
\text { Meadow in } \\
\text { seashore plain }\end{array}$ & $\begin{array}{c}\text { 滨海盐生草甸 } \\
\text { Meadow/saline meadow } \\
\text { in seashore }\end{array}$ \\
\hline 松 Pinus & & 4.72 & 13.93 & & \\
\hline 胡桃 Juglans & 2.22 & 1.90 & & & \\
\hline 桦 Betula & 2.83 & 1.16 & & & \\
\hline 柳 Salix & 0.90 & & & & 2.17 \\
\hline 栋 Quercus & 0.22 & 0.13 & & & \\
\hline 我耳枥 Carpinus & 0.71 & & & & \\
\hline 榛 Corylus & 0.33 & 0.05 & & & \\
\hline 杨 Populus & 0.33 & 0.13 & & & 0.32 \\
\hline 蓄薇科 Rosaceae & 0.86 & & 0.17 & 2.38 & \\
\hline 蒿 Artemisia & 6.85 & 10.87 & 5.63 & 21.26 & 0.51 \\
\hline 藜科 Chenopodiaceae & & 2.18 & 6.25 & & 5.67 \\
\hline 禾本科 Gramineae & & 1.45 & 0.26 & 0.23 & 0.07 \\
\hline 虎耳草科 Saxifragaceae & 0.14 & 0.26 & & & \\
\hline 唇形科 Labiatae & & 4.50 & & & \\
\hline 莎草科 Cyperaceae & & & 0.48 & 0.31 & \\
\hline 豆科 Leguminosae & & 0.63 & 0.05 & & \\
\hline 菊科 Compositae & 1.11 & 2.64 & 0.27 & & 0.04 \\
\hline 石竹科 Caryophyllaceae & & & 0.42 & & \\
\hline 香蒲 Typha & & & & & 1.99 \\
\hline 中华卷柏 Selaginella sinensis & 1.61 & & 7.94 & & \\
\hline
\end{tabular}


表 4 响山-北戴河剖面常见花粉 $R$ 值

Table 4 The $R$ value of common pollens in surface samples on Xiangshan-Beidaihe Section

\begin{tabular}{|c|c|c|c|c|}
\hline $\begin{array}{l}\text { 植物 } \\
\text { Plants }\end{array}$ & $\begin{array}{c}\text { 针阔混交林 } \\
\text { Coniferous and broad- } \\
\text { leaved mixed forest }\end{array}$ & $\begin{array}{c}\text { 针阔混交林与灌从 } \\
\text { Coniferous and broad-leaved } \\
\text { mixed forest and brushwood }\end{array}$ & $\begin{array}{c}\text { 滨海平原草甸 } \\
\text { Meadow in seashore plain }\end{array}$ & $\begin{array}{c}\text { 滨海草甸 } \\
\text { Meadow in seashore }\end{array}$ \\
\hline 松 Pinus & 2.10 & 21.19 & 14.95 & \\
\hline 栋 Quercus & 0.46 & 0.25 & 0.65 & \\
\hline 椴 Tilia & 0.16 & & & \\
\hline 栗 Castanea & & 10.18 & & \\
\hline 胡桃 Juglans & & 0.44 & & \\
\hline 木犀科 Oleaceae & 0.03 & & & \\
\hline 花椒属 Zanthoxylum & & 7.33 & & \\
\hline 榛 Corylus & & 0.45 & 0.13 & \\
\hline 蓄薇科 Rosaceae & 0.05 & 0.16 & & \\
\hline 蒿 Artemisia & 19.89 & 15.85 & 11.08 & 7.02 \\
\hline 藜科 Chenopodiaceae & 8.83 & 6.05 & & 1.71 \\
\hline 禾本科 Gramineae & 0.12 & 0.34 & 0.29 & 0.10 \\
\hline 毛茛科 Ranunculaceae & & 1.57 & 7.99 & \\
\hline 虎耳草科 Saxifragaceae & 0.30 & 0.26 & 0.69 & \\
\hline 葎草 Humulus & & & & 0.23 \\
\hline 蓼科 Polygonaceae & & & & 1.04 \\
\hline 豆科 Leguminosae & 0.11 & & & \\
\hline 唇形科 Labiatae & & & 13.13 & \\
\hline 菊科 Compositae & 3.15 & 2.17 & & 0.76 \\
\hline 莎草科 Cyperaceae & 0.01 & 1.18 & 0.08 & \\
\hline 旋花科 Convolvulaceae & & & & 0.21 \\
\hline
\end{tabular}

表 5 燕山地区常见花粉平均 $R$ 值

Table 5 The average $R$ value of common pollens in surface samples of Yanshan area

\begin{tabular}{|c|c|c|c|c|c|}
\hline 植物 Plants & $R$ & 植物 Plants & $R$ & 植物 Plants & $R$ \\
\hline 松 Pinus & 8.83 & 蔷薇科 Rosaceae & 1.00 & 毛茛科 Ranunculaceae & 3.62 \\
\hline 柳 Salix & 3.25 & 花椒属 Zanthoxylum & 7.33 & 葎草 Humulus & 0.98 \\
\hline 栋 Quercus & 0.32 & 蒿 Artemisia & 9.68 & 伞形科 Umbelliferae & 10.46 \\
\hline 栗 Castanea & 7.20 & 藜科 Chenopodiaceae & 7.20 & 唐松草 Thalictrum & 2.07 \\
\hline 桦 Betula & 2.32 & 禾本科 Gramineae & 0.27 & 莎草科 Cyperaceae & 0.41 \\
\hline 胡桃 Juglans & 1.18 & 菊科 Compositae & 1.28 & 豆科 Leguminosae & 0.26 \\
\hline 我耳枥 Carpinus & 0.71 & 香蒲 Typha & 5.89 & 石竹科 Caryophyllaceae & 0.42 \\
\hline 木犀科 Oleaceae & 0.03 & 虎耳草科 Saxifragaceae & 0.51 & 旋花科 Convolvulaceae & 0.21 \\
\hline 杨 Populus & 0.23 & 唇形科 Labiatae & 4.56 & 中华卷柏 Selaginella sinensis & 4.78 \\
\hline 榛 Corylus & 0.25 & 蓼科 Polygonaceae & 3.72 & & \\
\hline
\end{tabular}

就可能产生差别。所以, 在孢粉分析中, 加强植物生 态和植物区系方面的理解和认识可以弥补对孢粉与 植物关系理解上的不足。

4)孢粉鉴定: 这是困扰着广大孢粉工作者的一 个普遍存在的问题。就目前第四纪孢粉鉴定的水平 来说, 不准确的鉴定经常是难以避免的。

\section{$3.2 R$ 值变化及其原因}

同一花粉在不同的植被带中其 $R$ 值也有一定 的差异,一般地说在远离主要花粉源的植被中, 该花 粉的 $R$ 值偏低,而在花粉源产地则 $R$ 值偏高。如 松, 在雾灵山山地草甸中为 0.91 , 针阔混交林中为 4.04 ; 唐松草在山地草甸中为 1.20 , 针阔混交林中为
1.98 , 山地灌草从中为 3.02; 桦在都山桦木林中为 2.83 , 针阔混交林中为 1.16 。

在雾灵山顶以及接近山顶一带, 有华北落叶松 (Larix principis-rupprechtii) 生长, 而在雾灵山的山地 草甸带其花粉却具低代表性, 这表明华北落叶松花 粉不仅产量低, 不易保存, 而且花粉的降落速度大, 传播能力低, Dyakoveska 1937 年测试落叶松 (Larix) 花粉的降落速度为 $12.29 \mathrm{~cm}^{\circ} \mathrm{s}^{-1}$, 比栋花粉大两倍, 飞翔的可能速度为柇的 $1 / 10$ (王开发等, 1983)。在 海拔较低的植被带, 松花粉具超代表性, 而有些植 被带几乎无松生长, 说明松花粉产量大且飞翔能力 强, 从高海拔的松林生长的地方飘飞到低海拔的植 
被带。再如桦, 在雾灵山顶山地草甸中 $R$ 值为 3.24 , 针阔混交林中降为 2.03 , 而至海拔 $1120 \sim$ $1760 \mathrm{~m}$ 的范围内都有桦树生长, 桦粉个体小, 表面 纹饰较细或较平滑, 在随气流运动中由于摩擦力小 而不易沉降(李文漪, 1998), 在雾灵山桦粉随气流上 升, 可能导致花粉“爬山”现象, 导致雾灵山山地草甸 桦粉具超代表性。栋属花粉在燕山地区各植被带中 均具低代表性,有研究表明: 在以松为优势的针阔混 交林中,栋的 $R$ 值趋向减小(李文渏, 1998)。栗花 粉具超代表性与当地人工栽植板栗有关。

草本植物花粉中高属、藜科一般为超代表性, 二 者是草本植物花粉的主要组成成分, 在燕山地区各 植被带, 蒿属和藜科花粉含量普遍偏高, 这种现象与 二者花粉产量大、传播能力强有关。伞形科花粉只 在雾灵山山地草甸出现, 且具超代表性, 是局部环境 所致。禾本科花粉在该区各植被带中均具低代表 性, 而禾本科是草原和草甸的建群种, 常见有河北鹅 观草( Roegnera)、早熟禾 ( Poa )、假苇拂子茅( Calamagrostis pseudophragmites)、大籽蒿（Artemisia sieversiana) 和毛莲蒿 (Artemisia vestita) 等, 农作物有小麦 (Triticum aestivum)、水稻 (Oryza sativa) 和玉米 (Zea mays), 滨海地区的池塘沼泽中生长有芦苇( Phrangmites communis) 等, 其盖度大多为 $20 \% \sim 80 \%$, 甚至 到 $90 \%$, 可是在孢粉谱中的含量一般 $<5 \%$, 最高达 $13.22 \%$, 这可能说明禾本科花粉不易保存, 故为低 代表性, 新疆荒漠草原的表土孢粉资料也证实了这 一点(李文漪等, 1990), 此外, 黄土堆积物中尽管保 存有丰富的禾本科植物硅酸体, 但禾本科花粉却不 多(王苏民等, 1995)。

其次一些低代表性的花粉, 如虎耳草科、葎草、 莎草科、豆科、石竹科和旋花科等, 因目前资料不足， 无法具体讨论它们的情况。

另外,外来花粉可能是影响 $R$ 值的一个重要因 素, 因为由于外来花粉的加入,使得当地植物花粉在 孢粉组合中所占比例相应减少, 就有可能导致 $R$ 值 的减小。刘会平等(1998)研究认为样方面积也对 $R$ 值有影响,一般认为 $20 \mathrm{~m} \times 20 \mathrm{~m}$ 或以 $20 \mathrm{~m}$ 为半径 的样方面积比较合适, 过大、过小都会影响狍粉的 $R$ 值, 特别是对非优势种而言, 其影响尤为明显。
既然一种植物的 $R$ 值是随着地点不同而变化, 那么,仅根据一个或少数几个地点所得的 $R$ 值则难 以准确, 但是在研究一个地区的花粉与植被关系时, 用 $R$ 值均值来代表一个地区的某种植物的 $R$ 值还 是较为可行的。但是,怎样利用 $R$ 值更准确地恢复 历史时期的植被面貌，尚需深入研究。

\section{参 考 文 献}

Davis, M. B. 1963. On the theory of pollen analysis. American Journal of Science, 261: $897 \sim 912$.

Li, W. Y. (李文渏) \& Z. J. Yao(姚祖驹). 1993. Late quaternary vegetation and environment of north and middle subtropical region of China. Beijing: China Ocean Press. $104 \sim 109$. (in Chinese with English abstract)

Li，W. Y. (李文渏) \& S. Yan(阎顺). 1990. Study on quaternary palynology in Chaiwopu Basin. In: Shi, Y. F. (施雅风), Q.Z. Wen(文启忠) \& Y. G. Qu(曲耀光) eds. The quaternary climo-environment changes and hydrogeological condition of Chaiwopu Basin in Xinjiang region. Beijing: China Ocean Press. 46 74. (in Chinese)

Li, W. Y. (李文渏). 1998. Vegetation and environment of quaternary in China. Beijing: Science Press. (in Chinese)

Liu, H. P. (刘会平) \& L. D. Xie(谢玲娣). 1998. A study on the representation of some main pollens in Shennongjia region. Journal of Central China Normal University (Natural Science Edition) (华中师范大学学报 (自然科学版) ), 32: 495 497 . (in Chinese with English abstract)

Tong, G. B. (童国榜),X. D. Yang(羊向东),S. M. Wang(王 苏民）\& L. H. Xia(夏良华). 1996. Sporo-pollen dissemination and quantitative character of surface sample of ManzhouliDayangshu region. Acta Botanica Sinica(植物学报), 38:814 821. (in Chinese with English abstract)

Wang, K. F. (王开发) \& X. Z. Wang(王宪曾). 1983. Palynology outline. Beijing: Beijing University Press. 61 63. (in Chinese)

Wang, K. F. (王开发) \& X. Xu(徐馨) . 1988. Quaternary palynology. Guiyang: The People's Press of Guizhou. (in Chinese)

Wang, S. M. (王苏民)，L. Ji(吉否)，X. D. Yang(羊向东), B. Xue (薛滨), Y. Ma(马燕), B. Q. Qin (秦伯强), G. B. Tong(童国榜), H. X. Pan(潘红胥), S. Y. Hu(胡守云), W. L. Xia(夏威岗), J. Shen(沈吉), L. Xiang(项亮), L. R. Zhang(张立仁) \& Y. X. Zhu(朱育新). 1995. Paleolimnology of Hulun Lake. Hefei: University of Science and Technology of China Press. $42 \sim 75$. (in Chinese)

Xu, X. (徐馨), Q. Y. Cao(曹琼英), X. Y. Wang(王雪瑜), Z. H. Zhang (张之恒), X. X. Liu (刘雪䢞), K. Y. You (尤坤 元),C.H. He(何才华),K. F. Wang(王开发),Z.D. Shen (沈志达) \& P. Y. Chen (陈佩英). 1992. Study method on quaternary environment. Guiyang: Guizhou Science and Technology Press. (in Chinese)

Zhang, J. H. (张佳华)，Z. C. Kong(孔昭宸) \& N. Q. Du(杜 乃秋). 1996. Pollen analysis of surface samples from Baihua and Dongling Mountains in Beijing. Marine Geology and Quaternary Geology (海洋地质与第四纪地质), $16(3): 101 \sim 113$. (in Chinese with English abstract) 